\title{
Flebite de seios sigmóidee tranverso \& mastoidite de Bezold: relato de caso e revisão da literatura
}

\section{Sigmoid and transverse sinus' phlebitis \& Bezold's mastoiditis" case reportand literabure review}

\author{
Sérgio Bittencourt ${ }^{1}$, Ulisses J. Ribeiro ${ }^{1}$, \\ Paulo A. S. Vichi Jr. ${ }^{2}$, Fabrícia D. Colombano \\ Lys M. A. Gondim ${ }^{2}$, Elaine M. Watanabe
}

Palavras-chave: mastoidite de Bezold, flebite de seio sigmóide, flebite de seio transverso, complicações de otite média. Key words: Bezold's mastoiditis, sigmoid sinus' phlebitis, transverse sinus' phlebitis, otitis media's complications.

\section{Resumo / Summary}

bjetivo: descrever duas complicações raras de otite média aguda tratada inadequadamente. Método: descrição de um caso de duas complicações simultâneas de otite média aguda em um menino de 12 anos e realização de revisão da literatura. Resultados: Um paciente masculino, branco, de 12 anos, veio encaminhado de outro serviço por apresentar quadro de otite há dois meses, não responsivo ao tratamento clínico, evoluindo com massa cervical à direita. O exame clínico demonstrou membrana timpânica espessada e opacificada à direita, com discreto aumento da vascularização. O estudo radiológico evidenciou processo inflamatório/ infeccioso, envolvendo região mastóidea direita, com aspecto de múltiplos abscessos, estendendo-se extracranialmente para região cervical e presença de alterações sugestivas de flebite, envolvendo seios transverso e sigmóide direitos. Após ser submetido à cirurgia e antibioticoterapia endovenosa, o paciente apresentou boa evolução, com baixa morbidade. Conclusão: Apesar da baixa incidência de complicações das otites médias, devido ao avanço e uma maior abrangência no espectro da antibioticoterapia, não podemos nos abster da sua existência.

\begin{abstract}
A mescribe two rare complications of acute otitis media inadequately treated. Method: description of a case of two simultaneous complications of acute otitis media in a 12-year-old boy and a posterior literature review of the theme. Results: a 12-year-old white boy was referred to our ENT Department presenting 'otitis' for two months without improvement with the clinical treatment and evolving to a right cervical mass. At the clinic examination the otoscopic findings were a thickened and opaque tympanic membrane with a discreet increase on its vascularization. The radiologic exams showed an inflammatory/infectious process involving the mastoid region, with multiple abscesses aspect extending extra-cranially to the right cervical area and presence of suggestive alterations of phlebitis in the transverse and sigmoid right sinus. After surgical procedure and parenteral antibiotic therapy, the patient had a good evolution, with a low morbidity. Conclusions: despite the low incidence of the acute otitis media complications, due to the evolution and high spectrum of the antibiotic therapy, we must not forget they still exist.
\end{abstract}

${ }^{1}$ Chefe do Serviço de Otorrinolaringologia do Hospital Nossa Senhora de Lourdes. 2Médico(a) Residente do Serviço de Otorrinolaringologia do Hospital Nossa Senhora de Lourdes. Endereço para correspondência: Hospital Nossa Senhora de Lourdes Rua das Perobas, 344 04321-120 São Paulo - SP

Tel. (0xx11) 5018-4730 - Fax: (0xx11) 5011-0206 - E-mail: cehns1@uol.com.br Artigo recebido em 04 de dezembro de 2001. Artigo aceito em 14 de março de 2002. 


\section{INTRODUÇÃO}

A otite média é uma das infecções mais prevalentes. Com o desenvolvimento do espectro da antibioticoterapia, sua abordagem veio se modificando de um tratamento eminentemente cirúrgico, para medicamentoso. A incidência de complicações em muito diminuiu, sendo, atualmente, infreqüentes ${ }^{1,2,3}$. Na fase pré-antibiótica, as complicações intracranianas ocorriam em $2.3 \%$ dos casos, e as extracranianas em $0.45 \%$ deles $^{4}$, com uma redução drástica para 0.15 0.04\% respectivamente, após a introdução dos antibióticos. Apesar do declínio na incidência e no número absoluto das complicações, elas mantiveram suas distribuições e freqüências similares às da fase pré-antibiótica.

As complicações do processo infeccioso no ouvido médio se devem basicamente a uma extensão desta infecção para outras regiões do osso temporal (mastóide, região petrosa) e para o crânio (meninges, espaços meníngeos, parênquima) por contigüidade e, menos freqüentemente, pela via hematogênica. Dos fatores predisponentes, destacam-se: experiência do médico, mudança na virulência e susceptibilidade das bactérias, estado geral do paciente, evolução dos métodos diagnósticos de imagens, quadros mascarados por antibioticoterapia prévia inadequada, levando a diagnósticos tardios da afecção e da diminuição da pneumatização do osso temporal.

Tanto as otites médias agudas (OMA's) quanto as otites médias crônicas podem levar a complicações, tais como: mastoidite aguda, mastoidite de Bezold, mastoidite crônica, petrosite, labirintite, paralisia facial, fístula labiríntica, abscessos extra e subdurais, cerebrais e cerebelares, hidrocefalia otítica, meningite, sendo esta a mais comum, seguida pela tromboflebite sigmóide.

No presente artigo, os autores fazem relato de um caso de OMA com tratamento inadequado, em criança que apresentou simultaneamente complicação intracraniana (flebite de seios transverso e sigmóide direitos) e extracraniana (mastoidite de Bezold) e revisam a literatura sobre o tema.

\section{RELATO DE CASO}

H.M.P., 12 anos, masculino, branco, procedente de São Paulo - SP, apresentou, em janeiro de 2001, quadro de otalgia à direita e febre $\left(39^{\circ} \mathrm{C}\right)$, após a entrada de água nos ouvidos, sendo diagnosticado, em outro serviço, por um otorrinolaringologista, OMA, e medicado com Amoxacilina. No mesmo dia, devido a quadro de otalgia intensa, a mãe do menor procurou outro serviço de otorrinolaringologia (ORL) que, após o exame, substituiu a medicação vigente por Cefalexina (sete dias) e gotas nasais.

No início de fevereiro de 2001, o paciente continuava com otalgia à direita, afebril e, agora, com quadro de dor retroauricular e cervical à direita, hipoacusia e cefaléia. Foi medicado com antiinflamatório não esteroidal (AINE) e, após término do tratamento, persistiu com dor retroauricular direita e trismo.

Em 18/02/2001 foi realizada nova avaliação, por outro serviço de ORL que observou hiperemia de meato acústico externo e membrana timpânica (MT) direita, com espessamento, sendo realizado, na sala de observação, Cefalotina, Tenoxicam e Succinato de Hidrocortisona. Sem melhora clínica, o menor foi internado e solicitada avaliação do serviço de cirurgia buco-maxilo por provável disfunção de articulação têmporo-mandibular como hipótese diagnóstica. Foi transferido para hospital próprio do convênio, recebendo alta hospitalar no dia seguinte, com AINE e analgésico, por apresentar otoscopia normal.

Após uma semana, evoluiu com abaulamento cervical direito. Retornou, no dia 25/02/2001, ao último serviço de ORL que havia passado, sendo solicitado internação para investigação mais apurada do quadro e exames complementares. Foi solicitado hemograma, que mostrou discreta leucocitose, sem desvio à esquerda e tomografia computadorizada (TC) de crânio e pescoço (sem contraste), com sinais de osteomastoideopatia à direita (inflamatória?), sugerindo correlacionar com estudo tomográfico de ossos temporais (Figura 1). As TC's de ossos temporais e região cervical demonstraram lesão de aspecto misto em base de crânio/região cervical profunda à direita (abscesso? Outra etiologia?) (Figuras 2, 3). A possibilidade de extensão meníngea não foi descartada, além dos sinais de otomastodeopatia à direita.

Posteriormente, foram realizadas Audiometria, com disacusia condutiva moderada à direita (GAP de 30dB) e impedânciometria com curva $\mathrm{B}$ à direita e ausência de reflexos bilaterais.

O otorrinolaringologista daquele hospital sugeriu então realização de Ressonância Nuclear Magnética (RNM), em nosso hospital. Foi então que a equipe de radiologia solicitou a avaliação de nossa equipe de otorrinolaringologia (Hospital

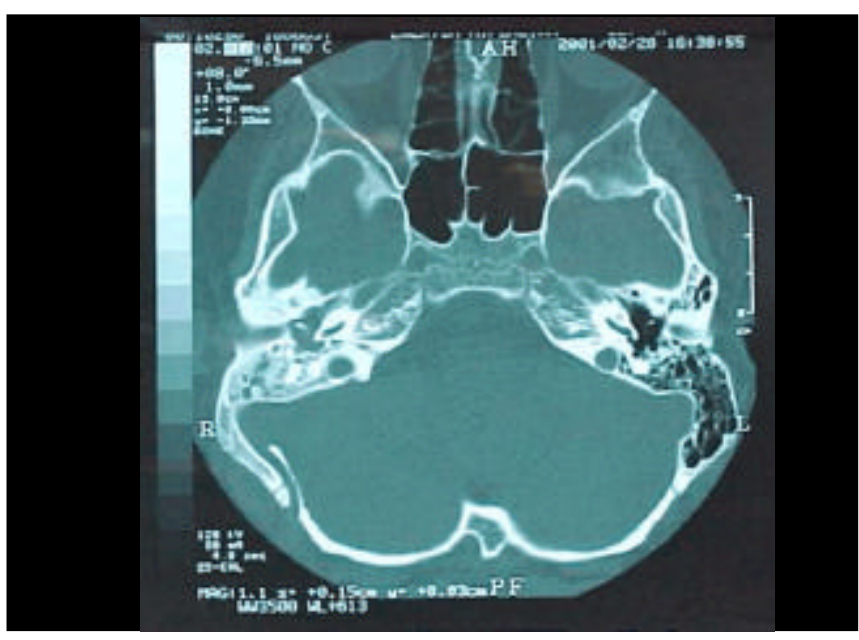

Figura 1. TC de Crânio (corte axial) 
Nossa Senhora de Lourdes) para reavaliação da RNM de mastóide, que evidenciou presença de processo inflamatório/ infeccioso, envolvendo região de mastóide direita, estendendo-se extracranialmente para região cervical (Figuras $4,5)$ e Angiografia Venosa que relatou ausência de fluxo no interior dos seios transverso e sigmóide direito, que apresentaram intenso realce ao contraste sugerindo flebite (Figuras 6, 7). Não foram observadas alterações indicando extensão do processo para espaço pericerebelar ou pericerebral.

O paciente ficou internado na nossa unidade com quadro de dor retroauricular direita, abaulamento e dor em região cervical látero-posterior direita, afebril, em bom estado geral, eupnéico e corado. Na otoscopia, a MT estava espessada e opacificada à direita, com discreto aumento da vascularização e a fundoscopia apresentava-se normal. Foi estabelecido o diagnóstico de mastoidopatia de Bezold e flebite dos seios transverso e sigmóide direitos.

Devido às complicações intra e extracranianas, optou-

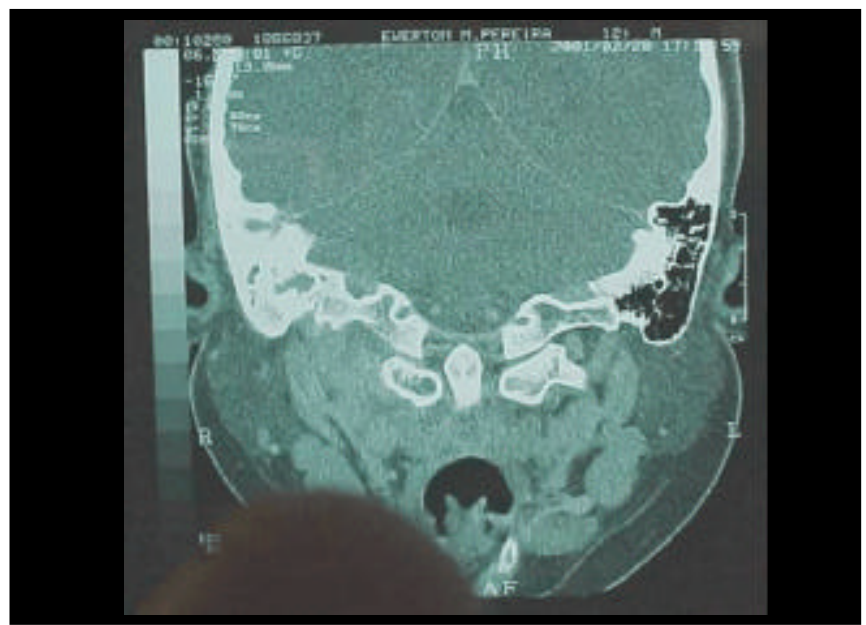

Figura 2. TC de Ossos Temporais (corte coronal)

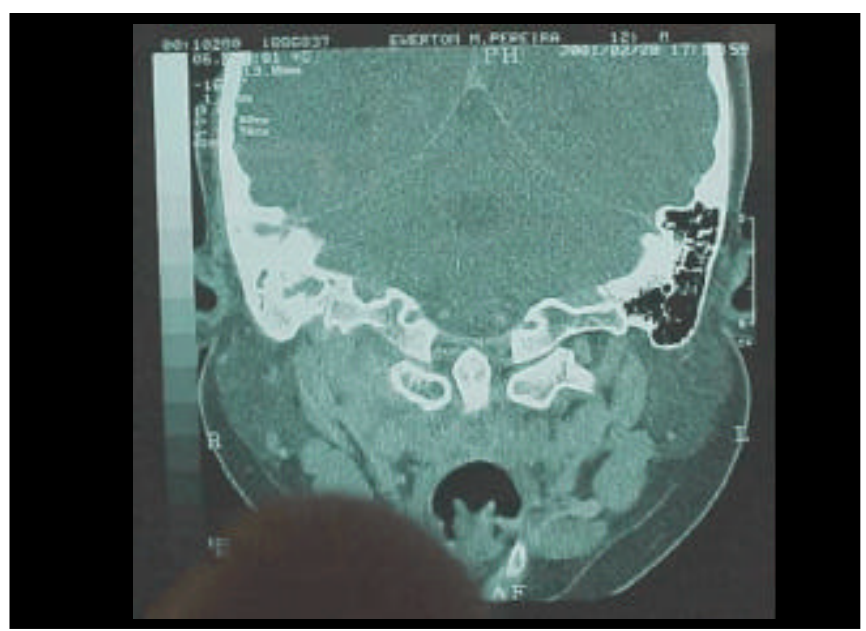

Figura 3. TC de Ossos Temporais (corte axial) se por uso de Ceftriaxone e Clindamicina e plano de mastoidectomia em ouvido direito. Durante a cirurgia, observou-se presença de tecido de granulação em abundância do córtex da mastóide e presença de fístula na ponta da mastóide, por onde foi drenada grande quantidade de exsudato purulento, especialmente à compressão do abaulamento cervical. Encontrada também grande quantidade de secreção no ouvido médio, optando-se por timpanotomia com colocação de tubo de ventilação à direita. Foram aspirados $50 \mathrm{ml}$ de exsudato enviado para estudo bacteriológico. No sítio do abscesso deixou-se um dreno de Penrose.

No pós-operatório imediato, evoluiu com tontura intensa e náuseas, sendo prescrito Pentoxifilina e Dimenidrato, Vitamina B6, Glicose, D-frutose. No segundo pós-operatório evoluiu sem tontura e ausência de secreção no dreno. Não apresentando complicações neurológicas e ausência de secreção no dreno, retirou-se o mesmo, recebendo alta hospitalar no terceiro pós-operatório com Ceftriaxone IM e Clindamicina VO. Após uma semana,

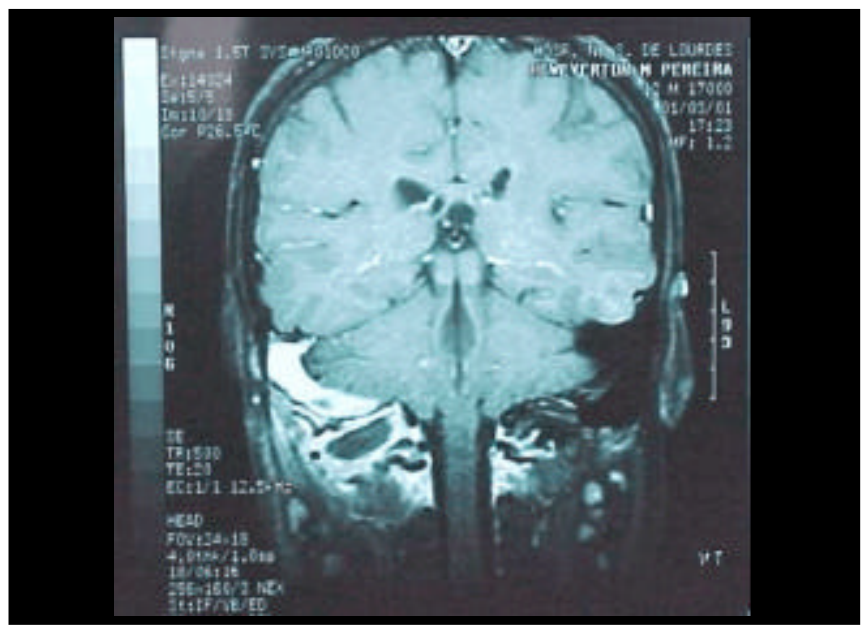

Figura 4. RNM (corte coronal)

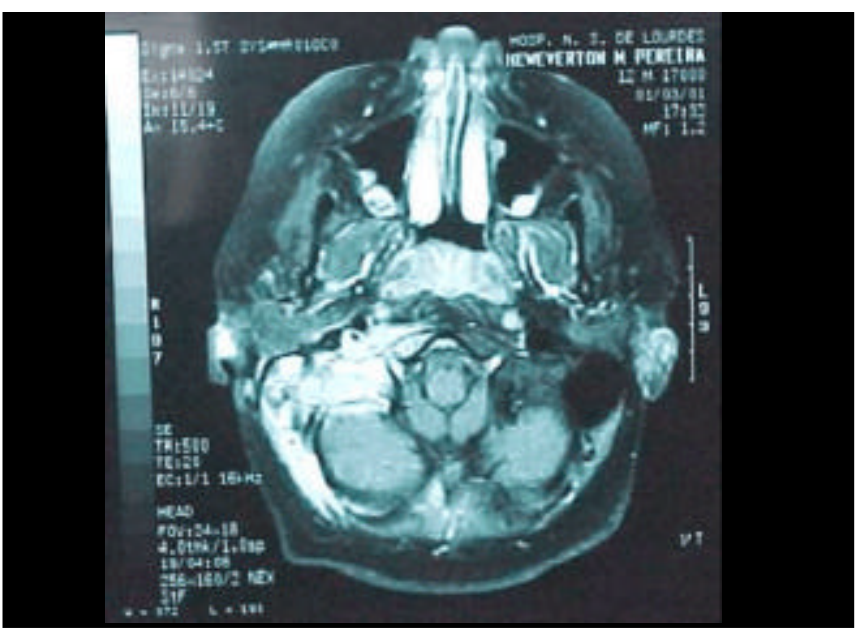

Figura 5. RNM (corte axial)

Revista Brasileira de Otorrinolaringologia 68 (5) Parte 1 Setembro/Outubro 2002 http://www.sborl.org.br / e-mail: revista@sborl.org.br 


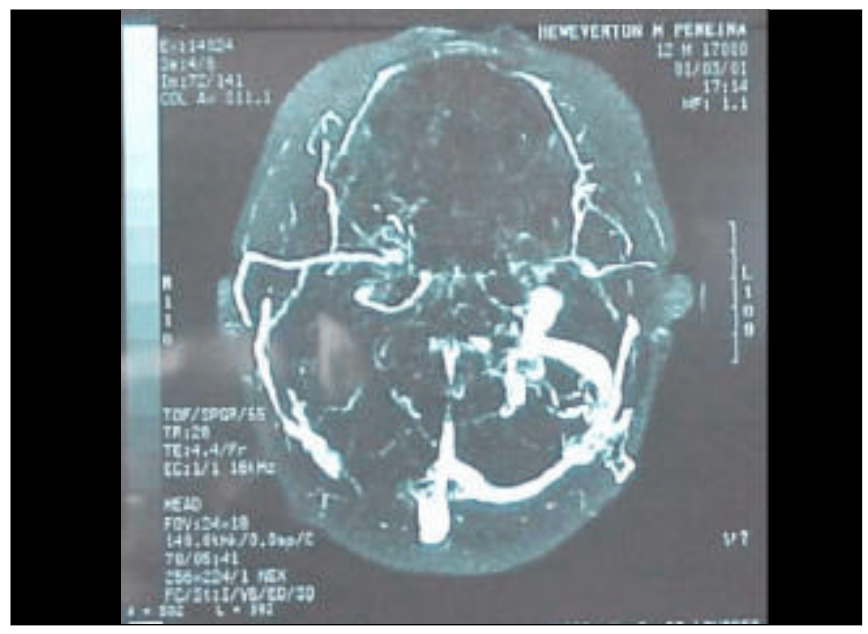

Figura 6. Angiografia Venosa

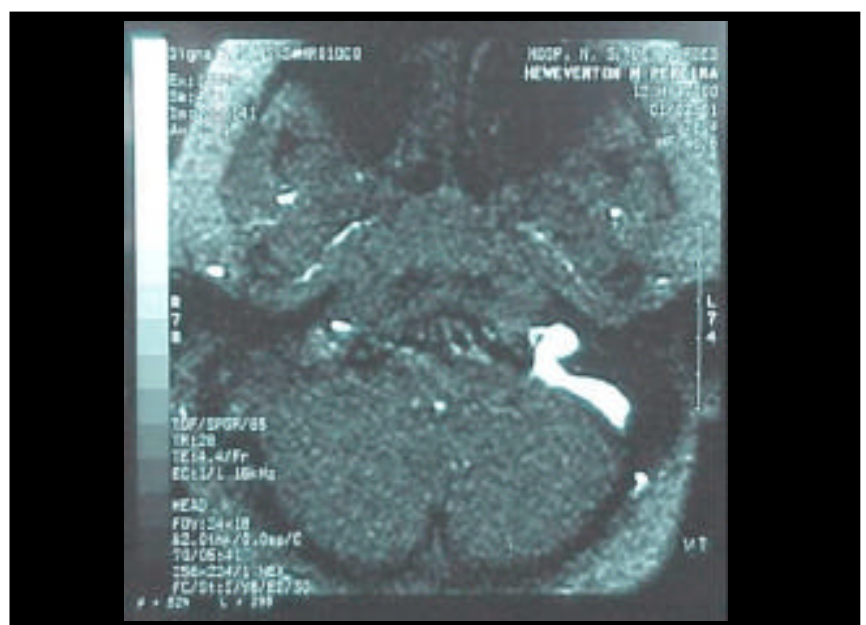

Figura 7. Angiografia Venosa

paciente retornou ao ambulatório assintomático, sendo realizada nova TC de ossos temporais (Fig. 8, 9) que evidenciou sinais de mastoidectomia parcial, notando solução de continuidade óssea em comunicação com a região de seio sigmóide. Há presença de conteúdo hipodenso no interior da caixa timpânica envolvendo a cadeia ossicular. Em relação ao exame anterior há ausência de coleção.

Atualmente, o paciente encontra-se em acompanhamento periódico ambulatorial, sem sinais aparentes de recidiva do processo e com Audiometria normal.

\section{DISCUSSÃO}

A tromboflebite do seio sigmóide é um processo inflamatório em torno do seio sigmóide, no espaço extradural, que acaba por estimular a formação do trombo, sendo a segunda complicação intracraniana mais comum. O paciente pode estar assintomático, ou, caso haja propagação para a

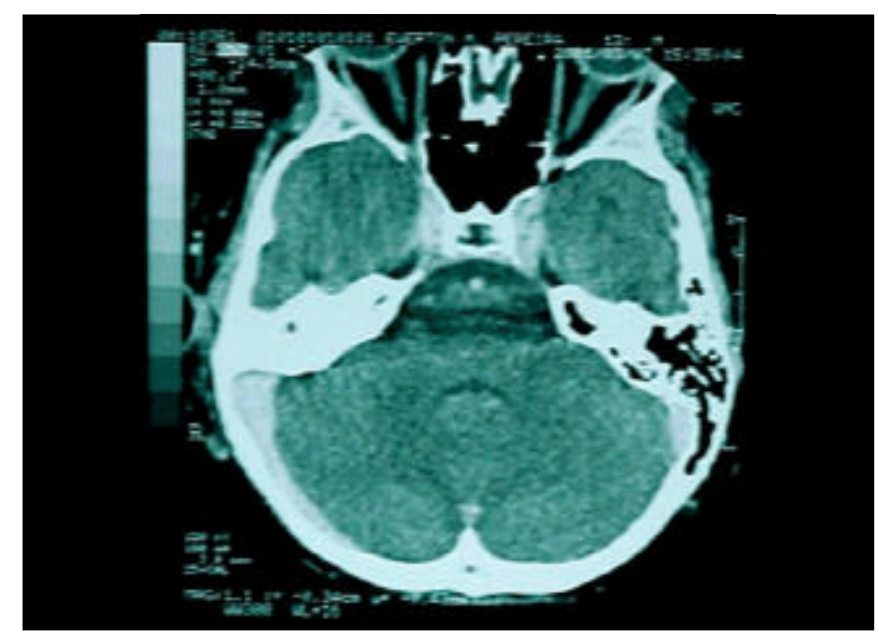

Figura 8. TC de Ossos Temporais - corte axial (pós-operatório)

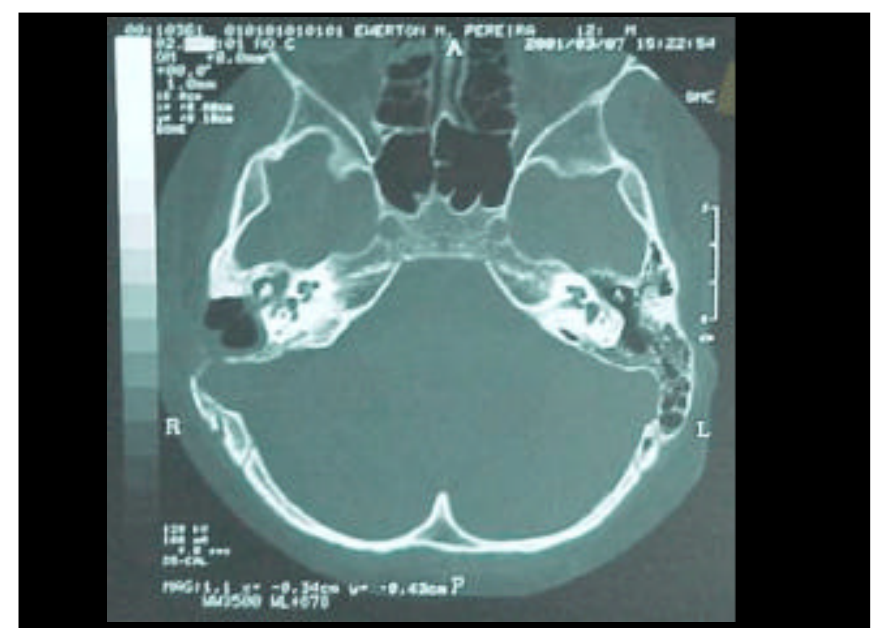

Figura 9. TC de Ossos Temporais - corte axial (pós-operatório)

veia jugular interna e bulbo jugular, conduzir à Síndrome do Forame Jugular, acarretando hipertensão intracraniana. É comum a associação de tromboflebite sigmóide com abscesso extradural. A mortalidade por trombose do seio sigmóide, devida à infecção do ouvido, na era antibiótica, variava de $2 \sim 3 \%$, tendo uma melhora marcante com o advento e evolução do tratamento cirúrgico.

Quanto à complicação extracraniana, apresentada pelo paciente, o abscesso de Bezold, este foi descrito em 1908, por Friedrich Von Bezold, um médico holandês, oftalmologista $^{5}$.

O abscesso de Bezold é uma complicação das otites médias, sendo definido quando há a propagação, a exteriorização do processo infeccioso do ouvido médio, através de uma fistulização da ponta da mastóide, formando subseqüente coleção purulenta cervical para o músculo esternocleidomastoideo. Se esta coleção purulenta caminhar para a face interna do músculo esternocleidomastoideo, pode

Revista Brasileira de Otorrinolaringologia 68 (5) Parte 1 Setembro/Outubro 2002 
ocorrer uma mediastinite anterior ${ }^{1}$.

No início do século XX, 50\% de todos os casos de OMA evoluíam para mastoidite. Por volta de 1959, esta incidência já caía para $0.4 \%$ e, felizmente, nos dias de hoje, ocorre em apenas $0.24 \sim 0.36 \%$ dos $\operatorname{casos}^{1,6}$. De 1988 a 1998, apenas 20 casos de abscessos látero-cervicais foram relatados na literatura mundial, incluindo nesta casuística os pacientes imunossuprimidos e também os abscessos de Mouret (jugo-digástrico).

O diagnóstico deve se basear na história clínica e exame físico e, muitas vezes, a duração dos sintomas acaba sendo fator mais importante que a severidade do quadro clínico presente. São casos, por vezes, oligossintomáticos, aparentemente sem gravidade e arrastados. Os casos podem ser considerados "mascarados", principalmente pelo não tratamento ou uso prévio e inadequado de antibióticos.

Quanto à microbiologia, podem ser causados pelos m esm osm icroorganism os responsáveispela OM Streptococcus pneumoniae e Haemophilus influenzae). Nos casos subagudos e crônicos, deve-se considerar o Staphylococcus aureus e as bactérias Gram negativas (Escherichia coli, Proteussp, Pseudomonas aeruginosa), lembrando ainda dos pacientes imunossuprimidos que podem ter como possíveis agentes causadores o Mycobacterium avium, Fusobacterium, entre outros ${ }^{1,3,5,7}$.

Os exames complementares, portanto, deixam de ser tão complementares, tornando-se verdade, indispensáveis para o próprio esclarecimento diagnóstico (determinando a localização exata e a extensão real do processo) e para a programação terapêutica.

A TC com contraste pode sugerir fortemente o diagnóstico. Um achado característico é a presença do "Sinal Delta" (ocasionado pela inflamação dos tecidos moles circunjacentes à dura-máter que reveste o seio lateral, impregnando-se com o contraste). A angiografia, em fase venosa, a RNM e a angiografia com subtração digital são os testes mais sensíveis para o diagnóstico ${ }^{3}$.

Na bacterioscopia, foram evidenciados cocos Gram positivos moderados e leucócitos abundantes. A cultura e a pesquisa de leveduras foi negativa. Resultados obtidos provavelmente pela utilização prévia de antibióticos ${ }^{1}$.

Dentre os fatores predisponentes para a infecção, encontramos, em nosso paciente, uma mastóide pouca pneumatizada, o que fortalece a literatura ${ }^{8}$.

Em relação ao tratamento, a terapia antimicrobiana de amplo espectro e com boa penetração na barreira hematoencefálica deve ser escolhida. A indicação de drenagem cirúrgica imediata, mastoidectomia e acompanhamento tomográfico posterior são mandatórios. Lembrando que o número de mastoidectomias, realizadas devidas a mastoidites e suas complicações, em 1938 era de 20\%, com uma queda para cerca de $2.8 \%$ em 1948, além de uma redução da mortalidade em $90 \%$ durante este mesmo período.

\section{COMENTÁRIOSFINAIS}

Apesar da raridade é preciso ter em mente que essas complicações ainda continuam presentes em nosso meio, principalmente porque o número absoluto de casos de mastoidites, como mencionado, tem diminuído, mas a proporção de abscessos de Bezold presentes nesses casos vêm aumentando (de 20\%, na época de Bezold, para 50\%, atualmente). Isto, devido aos diagnósticos serem freqüentemente tardios, na maioria das vezes, pelo mascaramento conseqüente a antibioticoterapia prévia e ausência de sintomas e/ou alterações à otoscopia.

As complicações extracranianas são mais comuns que as intracranianas, mas, estas, permanecem como causa importante de mortalidade em otites médias ${ }^{2,8}$.

Nos casos de suspeita de complicações otogênicas os exames radiológicos tornam-se essenciais e o tratamento cirúrgico deve ser realizado o mais rápido possível.

\section{REFERÊNCIASBIBUOGRÁFICAS}

1. Gaffney RJ, O'Dwyer TP, Maguirre AJ. Bezold's abscess. The Journal of Laryngology and Otology 1991;105:765-6.

2. Kangsanarak J, Fooanant S, Ruckphaopunt K, Navacharoen N, Teotrakul S. Extracranial and intracranial complications of supurative otitis media. Report of 102 cases. The Journal of Laryngology and Otology 1993;107:999-1004.

3. Saffer M, Lubianca JFN, Arrarte JLF, Brinckmann CA, Ferreira P. Tromboflebite do seio lateral e abscesso cervical como complicação de otite média crônica. Jornal de Pediatria 1997;74(4):269-72.

4. Spiegel JH, Lusting LR, Lee KC, Murr AH, Schindler RA. Contemporary Presentation and Management of a Spectrum of Mastoid Abscesses. Laryngoscope 1998;108:822-28.

5. Pappas DG. Friedrich Von Bezold (1842-1908) - ENT-Ear, Nose \& Throat Journal 1996;75:74-5.

6. Gower D, Mcguirt WF. Intracranial complications of acute and chronic infectious ear disease: a problem still us. Laryngoscope 1993;93:1028-33

7. Nadal D, Herrmann P, Baumann A, Fanconi A. Acute mastoiditis: clinical, microbiological, and therapeutic aspects. Ear J Pediatr 1990;149:560-4.

8. Kangsanarak J, Navacharoen N, Fooanant S, Ruckphaopunt K. Intracranial complications of supurative otitis media: 13 years experience. The American Journal of Otology 1995;16:104-9.

9. Monday LA. A propos d'une observation d'abcés de Bezold. L'union Médicale du Canada 1979;108:55-8.

10. Smouha EE, Levenson MJ, Anand VK, Parisier SC. Modern Presentation of Bezold's abscess. Arch Otolaryngol Head Neck Surg 1989;115:1126-9. 